\title{
Ursolic Acid Decreases the Proliferation of MCF-7 Cell-Derived Breast Cancer Stem-Like Cells by Modulating the ERK and PI3K/AKT Signaling Pathways
}

\author{
Gi Dae Kim \\ Department of Food and Nutrition, Kyungnam University, Gyeongnam 51767, Korea
}

\begin{abstract}
Cancer stem cells are strong drivers of metastasis and cancer relapse, which makes them important therapeutic targets. Ursolic acid (UA), a pentacyclic triterpenoid, has anticancer effects in various types of cancer; however, little is known about its effect on the growth of MCF-7 cell-derived breast cancer stem (BCS)-like cells in estrogen receptor positive breast cancer. In this study, the anticancer activity of UA in MCF-7 cell-derived BCS-like cells and its mechanism of action were evaluated. Furthermore, its inhibitory effects on the proliferation of MCF-7 cell-derived BCS-like cells were compared with that on MCF-7 cells. In MCF-7 cells, UA increased p53 and p21 expression but decreased cyclin D, cyclin E, CDK4, and CDK2 expression to induce cell cycle arrest in the G0/G1 phase. Moreover, UA significantly suppressed migration, invasion, and colony formation in MCF-7 cells, and suppressed mammosphere formation in a concentration-dependent manner. In MCF-7 cell-derived BCS-like cells, UA significantly decreased migration, suppressed p-PI3K, p-AKT, and p-ERK expression, and enhanced p-FoxO1/FoxO3a expression. Accordingly, in MCF-7 cell-derived BCS-like cells, UA suppressed proliferation in part by downregulating ERK and PI3K/AKT signaling pathways. These findings provide the first evidence for the selective effects of UA in BCSs.
\end{abstract}

Keywords: ERK, MCF-7 cell-derived breast cancer stem-like cells, PI3K/AKT, ursolic acid

\section{INTRODUCTION}

Breast cancer is one of the leading causes of mortality among women worldwide. Hormones and hormone receptors play important roles in the etiology of breast cancer (Brunetti and Manfioletti, 2019). Estrogen exerts a positive effect on cancer cell proliferation (Lumachi et al., 2015), with estrogen receptor (ER)-positive $(+)$ breast cancer accounting for approximately $80 \%$ of total breast cancer cases globally. Estrogen is a critical growth-stimulating and pro-survival agent in ER+ breast cancer cells, which activates proliferation-associated intracellular effectors, such as extracellular signal-regulated kinase (ERK) (Dérijard et al., 1995) and phosphoinositide (PI3K)/protein kinase B (AKT) (Thomas et al., 2006).

Cancer stem cells (CSCs) are a subpopulation of tumor cells with the capacity for self-renewal, differentiation, and tumorigenicity, in a similar way as normal stem cells (Wu and Chu, 2019). CSCs can cause onset and growth of tumors, with stronger resistance to chemotherapy and radiotherapy than non-CSCs (Visvader and Lindeman,
2008). Breast CSCs (BCSCs) contribute to the development of resistance to breast cancer therapy (Zhao, 2016) and cancer relapse and metastasis (Nandy and Lakshmanaswamy, 2017). Known BCSC markers include CD44, CD24, CD133, EpCAM, CD166, CD47, aldehyde dehydrogenase (ALDH), and ABCG2 (Shan et al., 2021). Unlike in typical breast cancer, BCSCs are not a target of $\mathrm{ER}+$ breast cancer endocrine therapy (Simões et al., 2011), and none of the currently approved drugs for ER+ breast cancer target CSCs. The probability of long-term disease-free survival increases upon total elimination of endocrine therapy-resistant BCSCs. Thus, development of therapies targeting CSCs is necessary.

Mitogen-activated protein kinase (MAPK, also known as ERK) is an enzyme that phosphorylates mitogen-activated proteins (Dérijard et al., 1995). The MAPK/ERK kinase (MEK)/ERK signaling pathway regulates cellular functions, such as proliferation, survival, and apoptosis (Reddy et al., 2003). In addition, the PI3K/AKT signaling pathway is involved in various cellular processes, including tumorigenesis, cell cycle progression, cell migration, 
cell invasion, and neovascularization in tumors (LoPiccolo et al., 2008). The PI3K/AKT pathway is aberrantly activated in most invasive breast cancers and may also promote the metastatic properties of CSCs (Marone et al., 2008; Singh et al., 2013). Thus, the PI3K/AKT pathway is a promising therapeutic target, and blocking this pathway may overcome resistance to conventional breast cancer therapies (Hernandez-Aya and Gonzalez-Angulo, 2011).

Several phytocompounds are effective chemopreventive or chemotherapeutic agents for breast cancer (Bak et al., 2016; Dandawate et al., 2016). Various epidemiological studies have suggested that fruit and vegetable intake can help to control numerous intracellular signaling pathways, suppress reactive oxygen species generation, prevent neovascularization and metastasis, promote metabolism, induce apoptosis, and promote cell cycle arrest in a positive feedback loop to substantially reduce the risk of developing breast cancer (Farvid et al., 2016; Grosso et al., 2017). Ursolic acid (UA; 3- $\beta$-hydroxy-urs-12-en-28oic acid) is a pentacyclic triterpene acid abundant in most fruits and vegetables. Most previous studies of UA have focused on its anticancer and antioxidant activity, pharmacological applications, and mechanism of action (Yeh et al., 2010; Yin et al., 2018; Liu et al., 2021). Indeed, UA induces G1/G2 cell arrest and inhibits breast cancer cell proliferation through controlling expression of major proteins in the signal transduction pathway (Shan et al., 2011). Moreover, UA induces breast cancer cell apoptosis via intrinsic and extrinsic apoptotic pathways (Kassi et al., 2009; Wang et al., 2012; Jiang et al., 2016). However, the fundamental molecular mechanism by which UA prevents progression and growth of breast cancer stem (BCS)-like cells remains unclear.
In this study, the anticancer activity of UA and its mechanisms of action were evaluated, focusing on its inhibitory effects against MCF-7 cell-derived BCS-like cell proliferation. To this end, we treated MCF-7 cells from $\mathrm{ER}+$ breast cancer cell lines not targeted by endocrine therapy with UA.

\section{MATERIALS AND METHODS}

\begin{abstract}
Materials
UA (Fig. 1A) was purchased from Sigma-Aldrich Co. (St. Louis, MO, USA). The compound was dissolved in $100 \%$ dimethyl sulphoxide (DMSO), and a $50 \mathrm{mmol} / \mathrm{L}$ stock solution was prepared and stored as small aliquots at $-20^{\circ} \mathrm{C}$ until use. DMSO, 3-(4,5-dimethylthiazol-2-yl)-2, 5-diphenyltetrazolium bromide (MTT), and horseradish peroxidase (HRP)-conjugated anti-rabbit and anti-mouse antibodies were purchased from Sigma-Aldrich Co.. Phycoerythrin-conjugated CD24 and fluorescein isothiocyanate (FITC)-conjugated CD44 antibodies were purchased from BD Biosciences (San Jose, CA, USA). The phosphospecific anti-p38, anti-PI3K, anti-AKT, anti-FoxO1/ FoxO3a antibodies, and specific anti-p38, anti-PI3K, antiAKT, anti-FoxO1/FoxO3a, ERK inhibitor PD98059, and AKT inhibitor LY294002 antibodies were purchased from Cell Signaling Technology (Danvers, MA, USA). HRP-conjugated $\beta$-actin, p53, p21, CDK4, cyclin D, CDK2, and cyclin $\mathrm{E}$ antibodies were purchased from Santa Cruz Biotechnology (Santa Cruz, CA, USA).
\end{abstract}

\section{Cell culture}

The human breast cancer cell line MCF-7 was obtained from the American Type Culture Collection (Rockville,
A

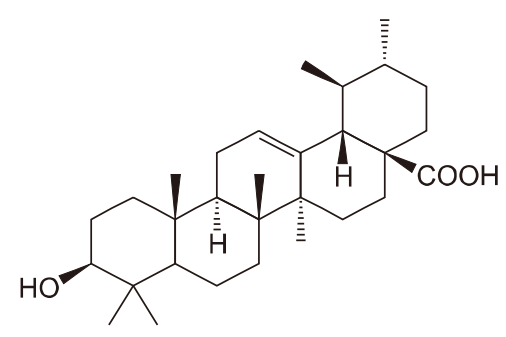

C

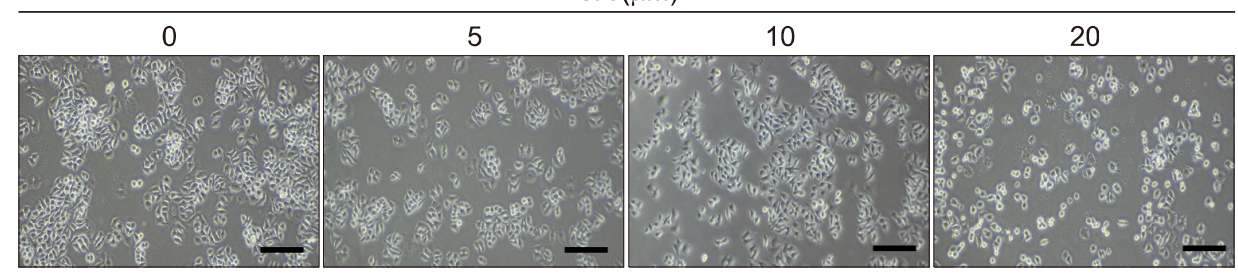

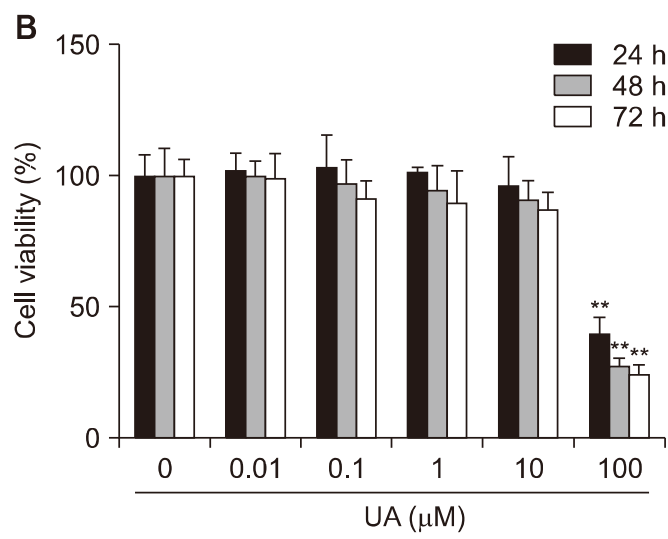

$\mathrm{UA}(\mu \mathrm{M})$
Fig. 1. Effect of ursolic acid (UA) on MCF-7 cell growth. (A) Chemical structure of UA. (B) Cell viability measured by MTT assays following incubation with $0,0.01,0.1,1,10$, and $100 \mu \mathrm{M}$ UA for 24,48 , and 72 h. Results are expressed as mean \pm SD. Statistical differences were analyzed using Student's $t$-test $\left({ }^{* *} P<0.01\right.$ vs. control). (C) Morphological changes. UA inhibited MCF-7 cell growth and resulted in rounded cell morphologies in a concentration-dependent manner. Cell morphology was visualized using inverted microscopy $(\times 200)$. Scale bar, $50 \mu \mathrm{m}$. MTT, 3-(4,5-dimethylthiazol2-yl)-2,5-diphenyltetrazolium bromide. 
MD, USA). Cells were cultured in Dulbecco's modified Eagle's medium (DMEM) supplemented with $10 \%$ fetal bovine serum (FBS) and $1 \%$ antibiotics-antimycotics in a $37^{\circ} \mathrm{C}$ humidified atmosphere with $5 \% \mathrm{CO}_{2}$. Cells were passaged every 3 to 4 days.

\section{Cell viability assay}

The viability of cells treated with UA was estimated using MTT assays. Cells were seeded in 96-well plates and, after culturing overnight, the primary culture medium was removed, and fresh medium containing six concentrations of UA $(0,0.01,0.1,1,10$, and $100 \mu \mathrm{M})$ was added for 24 to $72 \mathrm{~h}$. Then, $20 \mu \mathrm{L}$ of $5 \mathrm{mg} / \mathrm{mL}$ MTT in phosphate-buffered saline (PBS) was added to each well and cells were incubated for 3 to $4 \mathrm{~h}$. Next, the medium was removed and $200 \mu \mathrm{L}$ of DMSO was added to each well to stop the reactions. Cell viability was detected by measuring the optical density at $570 \mathrm{~nm}$ using a Synergy HTX plate reader (BioTek Instruments Inc., Winooski, VT, USA) and Gen5 (BioTek Instruments Inc.).

\section{Cell cycle analysis}

Cells were seeded into 100-mm diameter culture dishes, incubated for $24 \mathrm{~h}$, and then treated with UA $(0,5,10$, and $20 \mu \mathrm{M})$ for $48 \mathrm{~h}$. Cells were harvested using trypsin/EDTA and fixed with $70 \%$ cold ethanol overnight at $-20^{\circ} \mathrm{C}$. The fixed cells were centrifuged at $4^{\circ} \mathrm{C}$ at 5,000 rpm for $5 \mathrm{~min}$, washed with cold PBS, and incubated at $37^{\circ} \mathrm{C}$ for $30 \mathrm{~min}$ with $50 \mu \mathrm{g} / \mathrm{mL}$ RNase A. The cells were stained with $50 \mu \mathrm{g} / \mathrm{mL}$ propidium iodide at $37^{\circ} \mathrm{C}$ for 30 $\mathrm{min}$. The DNA contents of the stained cells were analyzed using CellQuest and a FACS Vantage SE flow cytometer (BD Biosciences, San Diego, CA, USA).

\section{Western blot analysis}

Cells were treated with UA $(0,5,10$, and $20 \mu \mathrm{M})$ for 24 to $48 \mathrm{~h}$ and lysed in PRO-PREP Protein Extraction Solution containing protease and phosphatase inhibitors (Roche Diagnostics $\mathrm{GmbH}$, Mannheim, Germany) for $30 \mathrm{~min}$ at $4^{\circ} \mathrm{C}$. Then, cells were centrifuged at $4^{\circ} \mathrm{C}$ at $13,000 \mathrm{rpm}$ for $30 \mathrm{~min}$. Whole protein samples $(40 \mu \mathrm{g})$ were separated using $6 \%$ to $12 \%$ sodium dodecyl sulfate-polyacrylamide gel electrophoresis and transferred onto polyvinylidene fluoride membranes (PVDF; Bio-Rad Laboratories Inc., Hercules, CA, USA). The membranes were blocked with $5 \%$ borine serum albumin (BSA) (AMRESCO, Cleveland, OH, USA) in Tris-buffered saline (TBS) with $0.1 \%$ Tween 20 (TBS-T) for $1 \mathrm{~h}$ at room temperature, then incubated with primary antibodies $(1: 500$ to $1: 1,000)$ diluted in $5 \%$ BSA in TBS-T overnight at $4^{\circ} \mathrm{C}$. Next, membranes were washed four times ( 3 min each) with TBS$\mathrm{T}$, and then incubated with HRP-conjugated anti-rabbit or anti-mouse secondary antibodies $(1: 1,000)$ for $1 \mathrm{~h}$ at room temperature. Protein bands were detected using an
Advanced Electrochemiluminescence Western Blot Detection Kit (Amersham, Uppsala, Sweden), and their intensities were measured using ImageJ (National Institutes of Health, Bethesda, MD, USA).

\section{Scratch wound-healing assays}

Approximately $5 \times 10^{5}$ cells were seeded into 6 -well plates and cultured for $24 \mathrm{~h}$. Artificial wounds were made in each well using a P20 pipette tip. The cells were washed with culture medium, and then fresh medium containing $1 \%$ FBS and UA $(0,5,10$, and $20 \mu \mathrm{M})$ was added. Images were captured at different time points $(24 \sim 72 \mathrm{~h})$ using an inverted microscope equipped with a camera. The wound gap distance was determined quantitatively using ImageJ (National Institutes of Health).

\section{Invasion assays}

Cell invasion assays were performed in 6-well plates containing Transwell inserts with 8- $\mu \mathrm{m}$ polycarbonate membranes (Corning Incorporated Costar, Tewksbury, MA, USA) (Yousefnia et al., 2020). Briefly, cells $\left(3 \times 10^{5}\right.$ cells $/ \mathrm{mL}$ ) in $1.5 \mathrm{~mL}$ of serum-free DMEM were plated in the upper chamber (BD BioCoat ${ }^{\mathrm{TM}}$ Matrigel $^{\mathrm{TM}}$ Invasion Chamber, Corning Life Science, Durham, NC, USA), and DMEM containing 10\% FBS was added to the lower chamber. In both the control and UA $(5 \sim 20 \mu \mathrm{M})$ treatment groups, after incubation at $37^{\circ} \mathrm{C}$ and $5 \% \mathrm{CO}_{2}$ for $48 \mathrm{~h}$, the non-invading cells were removed from the upper chamber with a cotton swab. The invading cells were fixed in $4 \%$ paraformaldehyde for $30 \mathrm{~min}$, stained with $0.5 \%$ crystal violet solution for $30 \mathrm{~min}$, and counted in microscopic fields.

\section{Colony formation assays}

Cells were seeded at a density of 1,000 cells/well in 6well flat-bottom plates with $2 \mathrm{~mL}$ of DMEM containing $10 \%$ FBS. The cells were cultured for $24 \mathrm{~h}$ with or without UA, the medium was replaced, and cells were cultured at $37^{\circ} \mathrm{C}$ in a $5 \% \mathrm{CO}_{2}$ incubator for a further 14 days. Cell colonies were fixed in methanol and stained with crystal violet. Colonies that contained more than 50 cells were counted under a microscope.

\section{Mammosphere culture}

For analysis of mammosphere formation, MCF-7 singlecell suspensions were plated at $5 \times 10^{4}$ cells/well using the Mammocult ${ }^{\mathrm{TM}}$ Human Medium Kit (STEMCELL Technologies, Vancouver, BC, Canada). The cells were seeded into Ultra-Low Attachment 6-well plates at $37^{\circ} \mathrm{C}$ and $5 \%$ $\mathrm{CO}_{2}$ and, after 7 days of culture, primary mammospheres were collected by gentle centrifugation. Cells were grown as non-adherent spheres (termed mammospheres) with a size of $>60 \mu \mathrm{m}$. For secondary mammosphere formation, the protocols described by Lombardo et al. (2015) 
and Yousefnia et al. (2020) were followed. Mammospheres were incubated for 4 weeks, passaged on days 7 , 14,21 , and 28 , and observed under a phase-contrast microscope.

\section{Analysis of cell surface markers and ALDH activity by flow cytometry}

Tertiary mammospheres of MCF-7 cells were trypsinized to generate single cells. The recommended concentrations of human CD24-PE and CD44-FITC antibodies (BD Biosciences) were added to the cell suspensions, and the cells were incubated at room temperature in the dark for $30 \mathrm{~min}$. The cells were then washed with PBS and analyzed using a FACSCalibur Flow Cytometer (BD Biosciences) (Jafari et al., 2017). ALDH activity was assayed using an Aldefluor ${ }^{\mathrm{TM}}$ assay kit (STEMCELL Technologies). Cells treated with the ALDH inhibitor diethylaminobenzaldehyde (DEAB) were used as a negative control. ALDHpositive and ALDH-negative cells were sorted using a flow cytometer (BD Biosciences) (Choi et al., 2018).

\section{Statistical analysis}

Data were presented as mean \pm SD for the indicated number of independent experiments. Statistical significance $(P<0.05)$ was determined using the Student's $t$-test for paired data. Statistical analyses were performed using SPSS for Windows (version 23.0; IBM Corp., Armonk, NY, USA).

\section{RESULTS}

\section{UA suppresses growth and induces cell cycle arrest in MCF-7 cells}

To determine whether UA inhibits the growth of human breast cancer cells, MCF-7 cells were exposed to $0 \sim 100$ $\mu \mathrm{M}$ UA for $24 \sim 72 \mathrm{~h}$. After 24,48 , and $72 \mathrm{~h}, \mathrm{IC}_{50}$ values were $75.5 \mu \mathrm{M}, 66.1 \mu \mathrm{M}$, and $61.9 \mu \mathrm{M}$, respectively (Fig. 1B), suggesting that MCF-7 cells show significant sensitivity to UA in a concentration- and time-dependent manner $(P<0.01)$. Based on the effects on cell count and morphology (Fig. 1C), UA at a concentration of $<20 \mu M$ (no cytotoxicity) was used for subsequent analyses of its bioactivity.

Since UA can inhibit breast cancer cell proliferation, we investigated whether UA causes apoptosis by cell cycle arrest. MCF-7 cells were treated with various concentrations of UA $(0 \sim 20 \mu \mathrm{M})$ for $48 \mathrm{~h}$, and intracellular DNA content was quantified by flow cytometry. MCF-7 cells treated with UA showed considerable cell accumulation, as indicated by an increase in the proportion of cells in the G0/G1 phase from $42.70 \%$ to $74.36 \%$ in the $20 \mu$ M UA-treated group compared with the control $(P<$ 0.01; Fig. 2A and 2B). To identify the molecular events associated with UA-induced growth arrest in MCF-7 cells, Western blotting was performed to detect various cell cycle regulatory proteins. MCF-7 cells were treated with varying concentrations of UA $(5,10$, and $20 \mu \mathrm{M})$ for 48 $\mathrm{h}$, resulting in an increase in $\mathrm{p} 38$ MAPK phosphorylation. Western blotting revealed that UA treatment in-
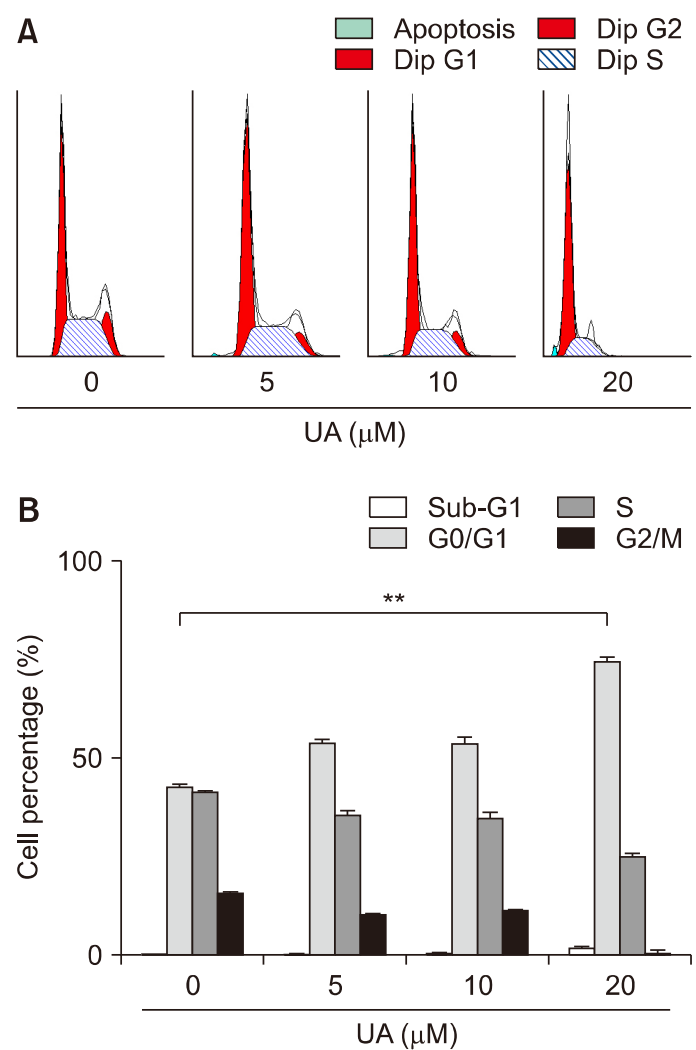

C

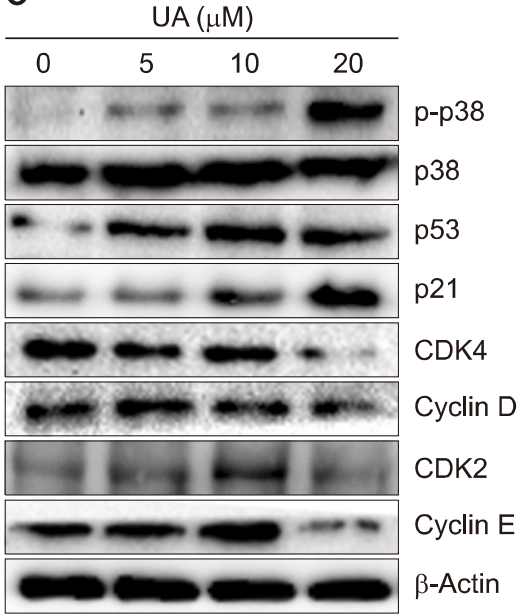

Fig. 2. Effect of ursolic acid (UA) on cell cycle progression in MCF-7 cells. (A) Flow cytometry analyses of the distribution of the stages of the cell cycle in MCF-7 cells stained with propidium iodide. MCF-7 cells were treated with $\cup A(0,5,10$, and $20 \mu \mathrm{M})$ for $48 \mathrm{~h}$. (B) The percentage of cells accumulated at GO/G1, S, and G2/M phases of the cell cycle depending on the cell type. Results are expressed as mean $\pm S D$. Statistical differences were analyzed using Student's $t$-test $\left({ }^{* *} P<0.01\right.$ vs. control). (C) Expression of the G0/G1related proteins $\mathrm{p}-\mathrm{p} 38, \mathrm{p} 38, \mathrm{p} 53$, p21, CDK4, cyclin D, CDK2, and cyclin $E$, examined by Western blotting. 
creased expression of p53 and p21, and decreased expression of $\mathrm{CDK} 4$, cyclin $\mathrm{D}, \mathrm{CDK} 2$, and cyclin $\mathrm{E}$ proteins (involved in the regulation of the G0/G1 phase), in a concentration-dependent manner (Fig. 2C).

\section{UA inhibits migration, invasion, and colony formation of MCF-7 cells}

To examine cell migration, a scratch was introduced into the cell monolayer to create a gap, and the rate of wound healing was analyzed under various concentrations of UA over $48 \mathrm{~h}$ (Fig. 3A and 3B). The wound area was inhibited by $52.2 \%$ for MCF-7 cells treated with $0 \mu \mathrm{M}$ UA and $1.2 \%$ for cells treated with $20 \mu \mathrm{M} \mathrm{UA}$, indicating significant inhibition in cell migration after UA treatment $(P<$ 0.001 ). For the migration assay, the concentration of FBS in the culture medium decreased from $10 \%$ to $1 \%$ to allow cells to migrate without proliferation. In addition, to evaluate the inhibitory effect of UA on cell migration and invasion, Boyden chamber assays were performed by treating cells with UA for $48 \mathrm{~h}$ (Fig. 3C and 3D). Consistent with the results of the wound-healing assay, the invasive capacity of MCF-7 cells was significantly inhibited by $4.8 \%$ and $0.24 \%$ after treatment with $10 \mu \mathrm{M}$ and $20 \mu \mathrm{M}$ UA, respectively $(P<0.001)$.

To evaluate the inhibitory effect of UA on colony formation, MCF-7 cells were exposed to various concentrations of UA for $24 \mathrm{~h}$, the medium containing UA was removed, and cells were cultured in fresh medium for 14 days (Fig. 3E and 3F). The mean colony number was significantly lower after treatment with $20 \mu \mathrm{M}$ UA than for control cells $(P<0.001)$. These in vitro results suggest that UA inhibits breast cancer progression by suppressing cell proliferation, migration, and invasion.
A

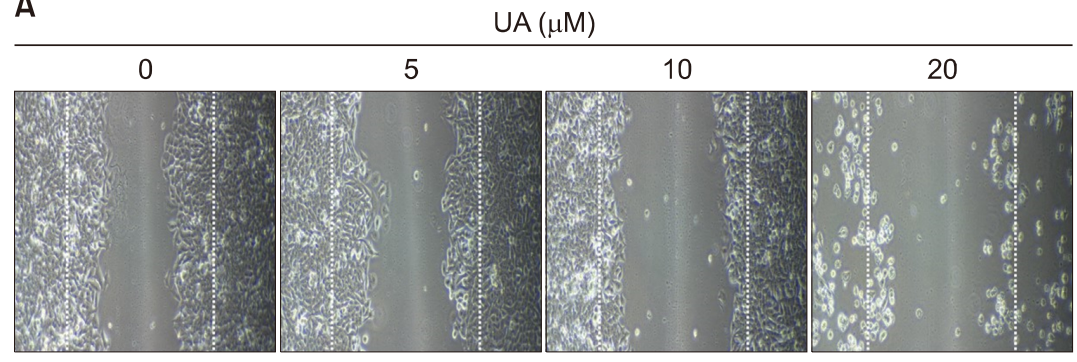

C

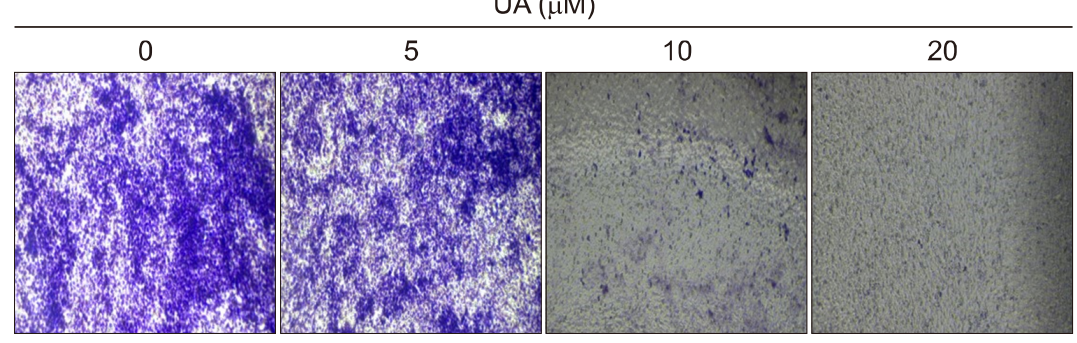

E

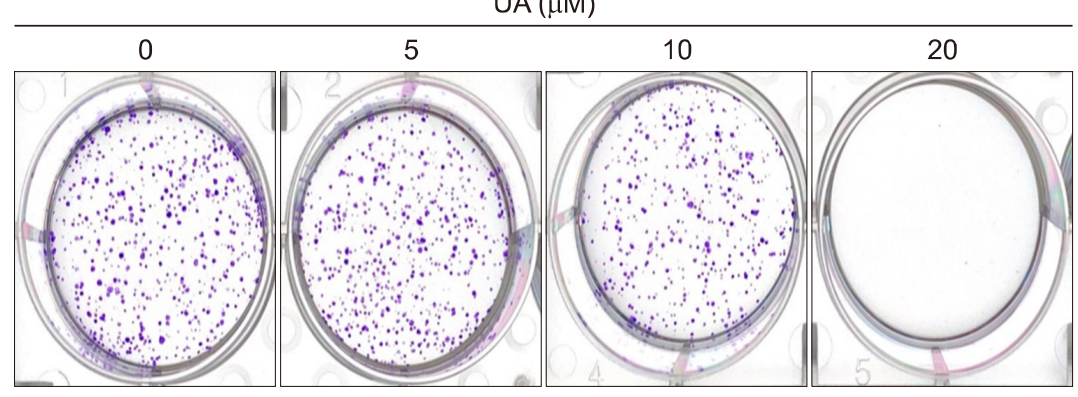

B
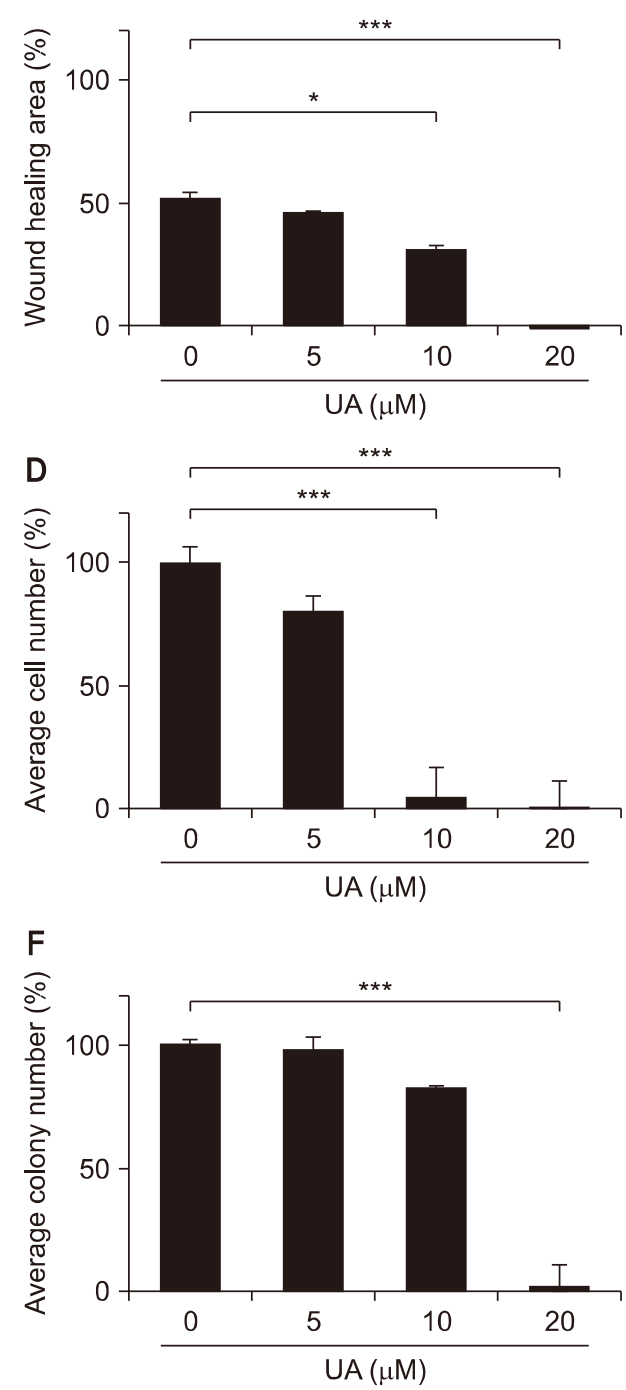

Fig. 3. Effect of ursolic acid (UA) on migration, invasion, and colony formation of MCF-7 cells. (A) Cells were grown to confluence in 6-well plates, scratch-wounded, and treated with the various concentrations of UA. (C) The filter membranes were coated with Matrigel and $0.02 \%$ gelatin. MCF-7 cells were treated UA for $48 \mathrm{~h}$. (E) Cells were seeded onto 6-well cell culture plates and stained with $0.5 \%$ crystal violet. (B, D, and F) The wound area, invading cell number, and colony number were measured using Image J. Values are presented as mean \pm SD. ${ }^{*} P<0.05$ and ${ }^{* * *} P<0.001$ vs. control. 
A

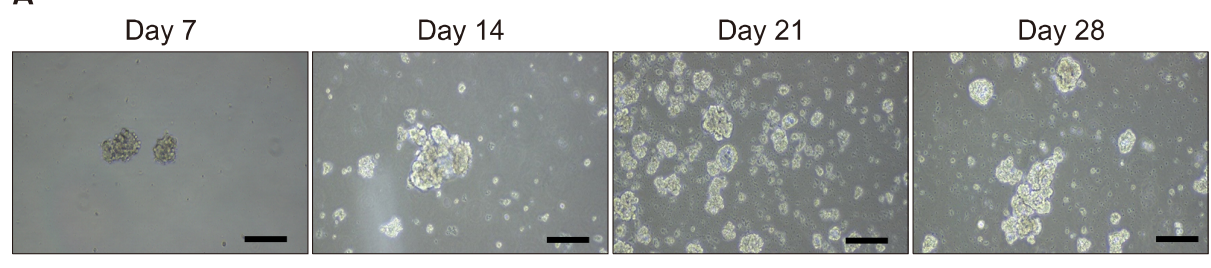

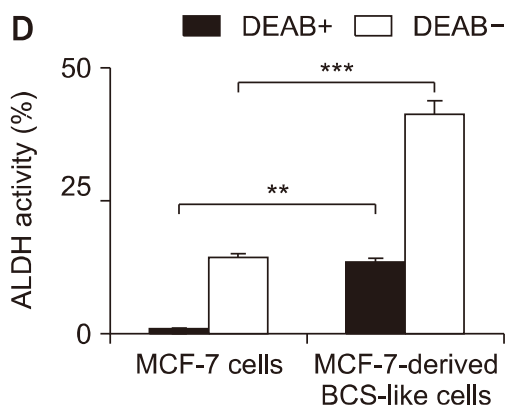

B

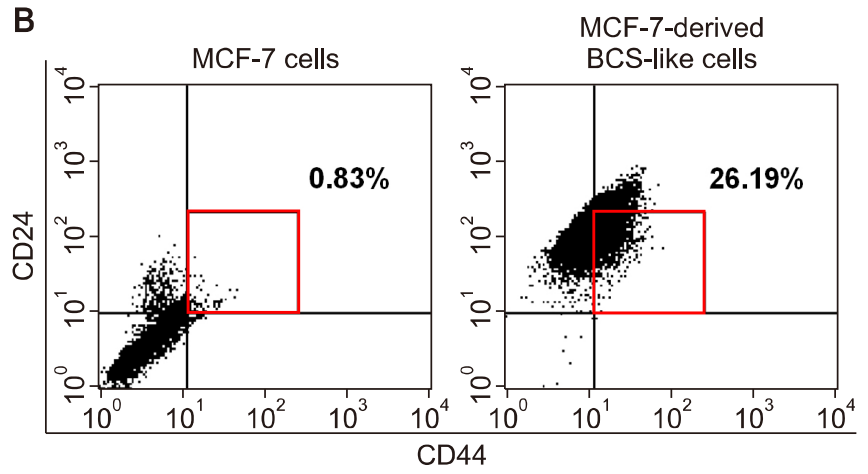

C

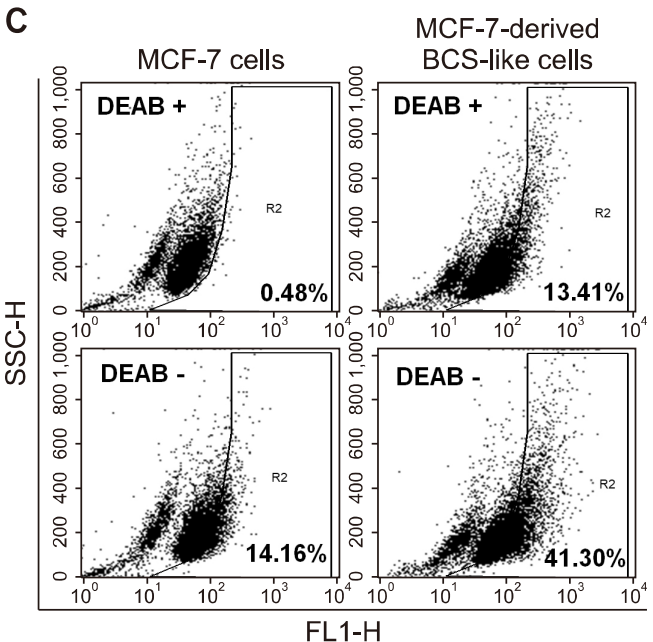

Fig. 4. Characteristics of MCF-7 cells after induction of differentiation. (A) To establish mammospheres, cells were seeded into 6-well plates in cancer stem cell culture media for 28 days, and phase-contrast microscopy was used to monitor mammosphere growth. Cell morphology was visualized using inverted microscopy $(\times 100)$. Scale bar, $200 \mu \mathrm{m}$. (B) CD44 $/$ CD24 $4^{-/ 10 w}$ populations were evaluated in MCF-7 cells and MCF-7 cell-derived breast cancer stem (BCS)-like cells. The square indicates the distribution of the $\mathrm{CD}_{4} 4^{+} / \mathrm{CD} 24^{-/ \text {low }}$ cell subpopulation. ( $\mathrm{C}$ and D) Aldehyde dehydrogenase (ALDH) expression in human BCS-like cells, analyzed by flow cytometry. Diethylaminobenzaldehyde (DEAB) was used as the specific ALDH inhibitor in the negative control groups. The gating was based on binding to a control antibody. Results are expressed as mean \pm SD. Statistical differences were analyzed with Student's $t$-test $\left({ }^{* *} P<0.01\right.$ and ${ }^{* * *} P<0.001$ vs. control). SSC-H, side scatter-height.

\section{Characterization of MCF-7 cell-derived BCS-like cells}

MCF-7 cells were monitored for mammosphere formation after induction of BCSC differentiation and subsequent culture in differentiation medium for 28 days. After induction of BCSC differentiation, the size and number of the mammospheres were increased (Fig. 4A), and the $\mathrm{CD} 44^{+} / \mathrm{CD} 24^{- \text {low }}$ cell fraction was increased from $0.83 \%$ to $26.19 \%$ (Fig. 4 B). In addition, there was an increase in the ALDH-positive cell population, from 14.16 $\%$ to $41.30 \%$, compared with parental MCF-7 cells ( $P<$ 0.001) (Fig. 4C). The proportion of ALDH-positive cells in the group treated with DEAB, an ALDH inhibitor, was $13.41 \%$, which was two thirds lower than that of MCF-7 cell-derived BCS-like cells (Fig. 4C and 4D). Thus, differentiation-induced MCF-7 cells show characteristics of BCSCs.

\section{UA significantly inhibits growth of MCF-7 cell-derived BCS-like cells}

The inhibitory effect of UA on cell proliferation by concentration and exposure time was evaluated in MCF-7 cells and MCF-7 cell-derived BCS-like cells treated with
$0 \sim 40 \mu \mathrm{M}$ UA. Growth inhibition analysis revealed that the $\mathrm{IC}_{50}$ values for MCF-7 cells and MCF-7 cell-derived BCS-like cells were $35.27 \mu \mathrm{M}$ and $27.90 \mu \mathrm{M}$, respectively, after $24 \mathrm{~h}$ and decreased to $20.97 \mu \mathrm{M}$ and $17.65 \mu \mathrm{M}$, respectively, after $72 \mathrm{~h}$ (Fig. 5). These results suggest that the inhibitory effect of UA on cell proliferation was greater in MCF-7 cell-derived BCS-like cells than in MCF-7 cells $(P<0.01$ and $P<0.001$, respectively).

\section{UA inhibits mammosphere formation and migration in MCF-7 cell-derived BCS-like cells}

To determine whether mammosphere formation is suppressed by UA, MCF-7-derived mammospheres were treated with UA for $48 \mathrm{~h}$. Medium containing UA was removed and cells were cultured in fresh medium for monitoring. Treatment with $20 \mu \mathrm{M}$ UA led to a significant decrease in mammosphere size by $80.3 \%(P<0.01$; Fig. 6). In wound healing assays, scratches were introduced into MCF-7 cell-derived BCS-like cell monolayers, and cells were exposure to various concentrations of UA for $48 \mathrm{~h}$ (Fig. 6C). Treatment with $0 \mu \mathrm{M}$ and $20 \mu \mathrm{M}$ UA decreased the wound area by $51.2 \%$ and $7.2 \%$, respec- 

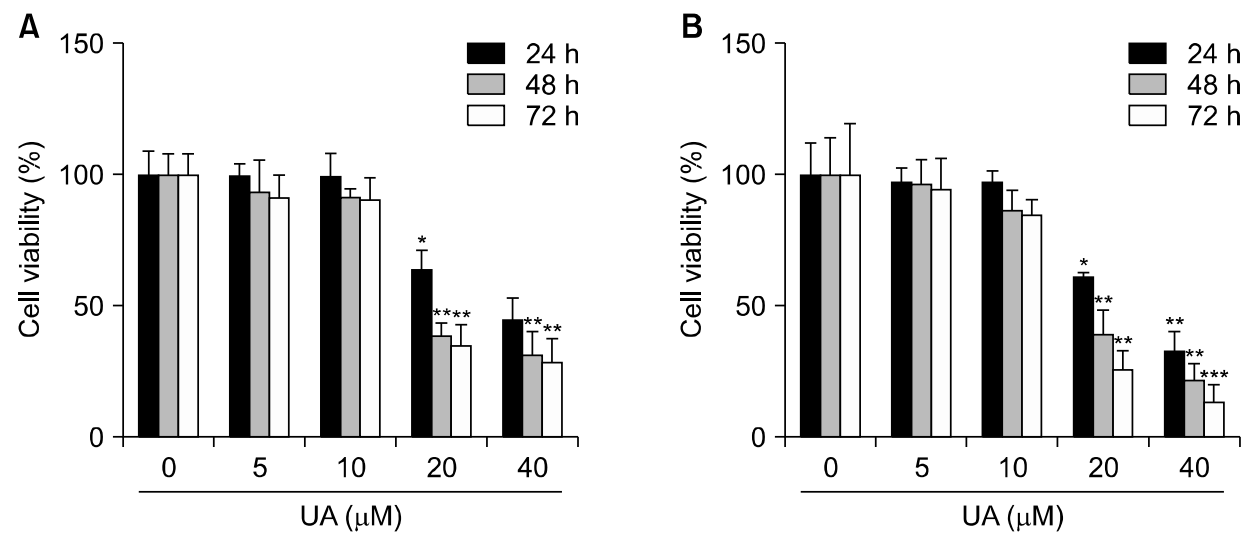

Fig. 5. Ursolic acid (UA) exerts cytotoxicity in MCF-7 cells and MCF-7 cell-derived breast cancer stem (BCS)-like cells. Comparison of cell viability in MCF-7 cells (A) and MCF-7 cell-derived BCS-like cells (B) by MTT assays following incubation with UA (0, 5 , 10,20 , and $40 \mu \mathrm{M}$ ) for 24,48 , and $72 \mathrm{~h}$. UA inhibited MCF-7 cell and MCF-7 cell-derived BCS-like cell growth in dose- and time-dependent manners compared with control cells. Results are expressed as mean \pm SD. Statistical differences were analyzed using Student's $t$-test ( ${ }^{*} P<0.05,{ }^{* *} P<0.01$, and ${ }^{* * *} P<0.001 \mathrm{vs}$. control). MTT, 3-(4,5-dimethylthiazol-2-yl)-2,5-diphenyltetrazolium bromide.

A

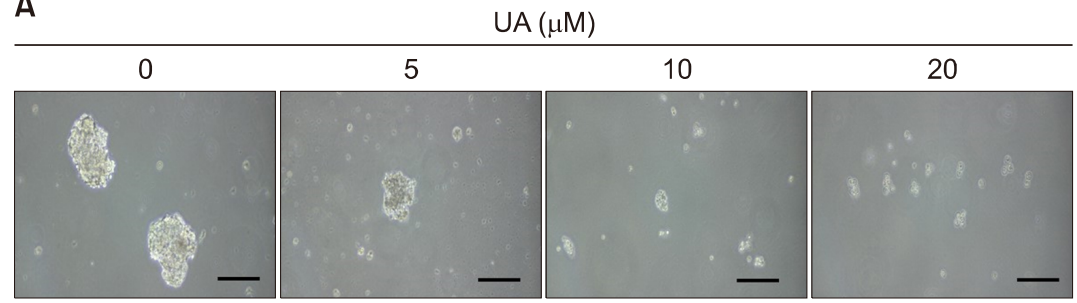

C

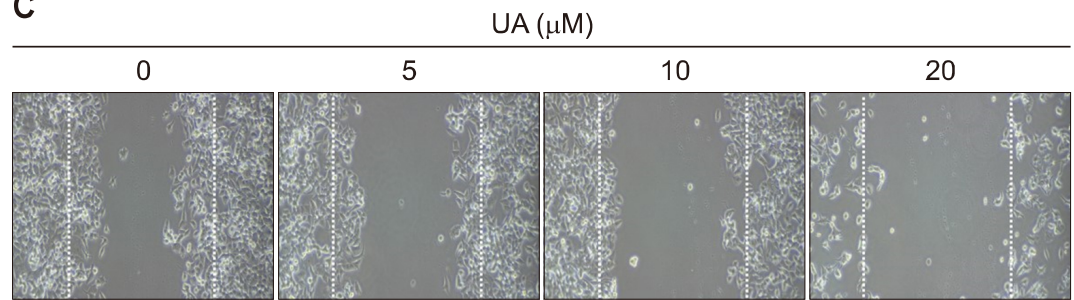

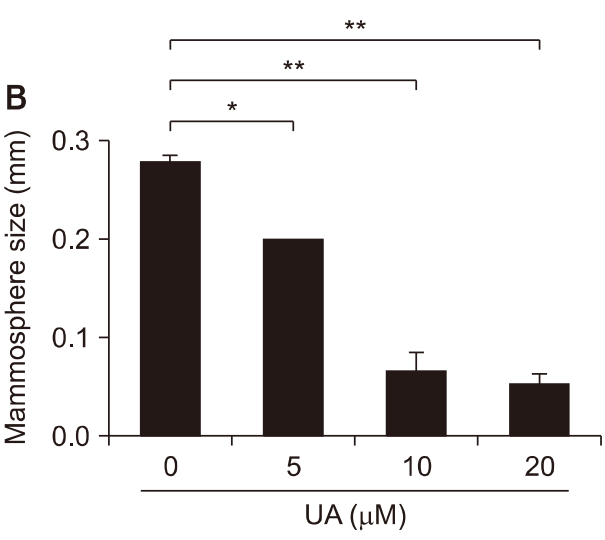

D

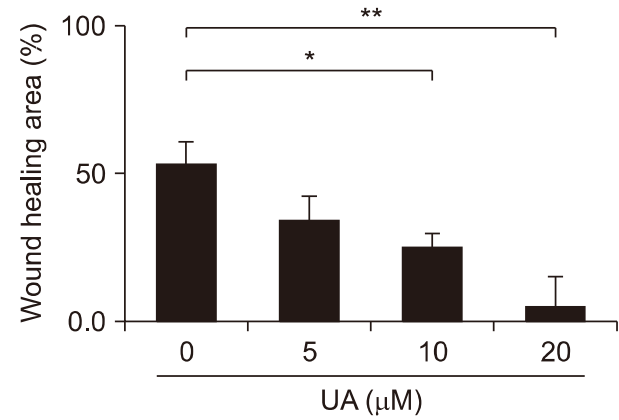

Fig. 6. Effect of ursolic acid (UA) on mammosphere-forming ability and migration of MCF-7 cell-derived breast cancer stem (BCS)-like cells. (A) Cells were treated with UA $(0,5,10$, and $20 \mu \mathrm{M})$ in ultra-low 6-well plates for 48 hours, the UA-containing medium was removed, and cells were incubated for 28 days to induce mammosphere formation. Phase-contrast microscopy was used to monitor mammosphere growth over 28 days. Cell morphology was visualized using inverted microscopy $(\times 100)$. Scale bar, $200 \mu \mathrm{m}$. (B) Quantitative analysis of mammosphere size. (C) Effect of UA on the migration of MCF-7 cell-derived BCS-like cells. Cells were grown to confluence in 6-well plates coated with $0.02 \%$ gelatin, scratch-wounded, and treated with various concentrations of UA for $48 \mathrm{~h}$. (D) The percentage distribution of the average wound area, as measured using ImageJ. Results are presented as mean $\pm \mathrm{SD}$. ${ }^{*} P<0.05$ and ${ }^{* *} P<0.01$ vs. control cells.

tively, indicating a significant reduction in cell migration with UA $(P<0.01$; Fig. 6D).

\section{UA suppresses ERK and PI3K/AKT signaling pathways in MCF-7 cell-derived BCS-like cells}

We next investigated the effects of UA $(5,10$, and 20 $\mu \mathrm{M})$ on expression of components of the PI3K/AKT sig- naling pathway in MCF-7 cell-derived BCS-like cells by Western blotting (Fig. 7A). p-PI3K, p-AKT, and p-ERK expression in MCF-7 cell-derived BCS-like cells was downregulated following UA treatment. Furthermore, UA treatment increased expression of p-FoxO1/FoxO3a. When cells were co-treated with UA and PD98059, an ERK inhibitor, or LY-294002, an AKT inhibitor (Fig. 7B and 7C), 
A

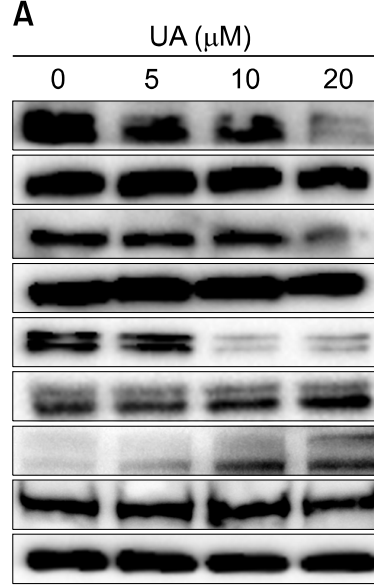

D

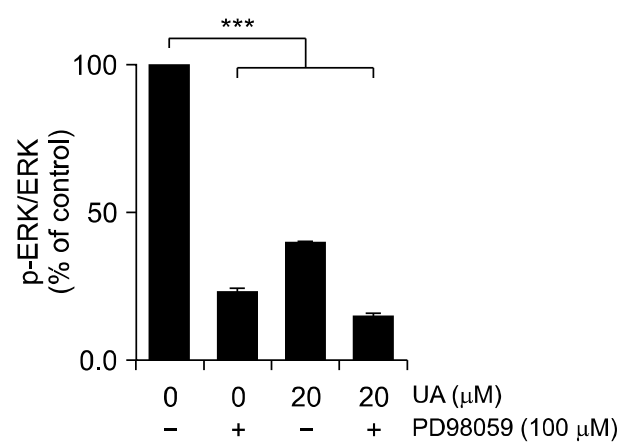

B

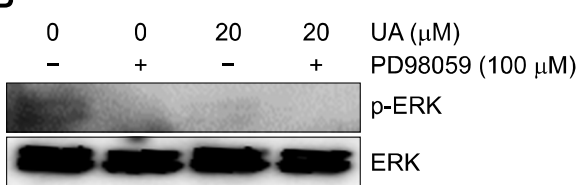

C

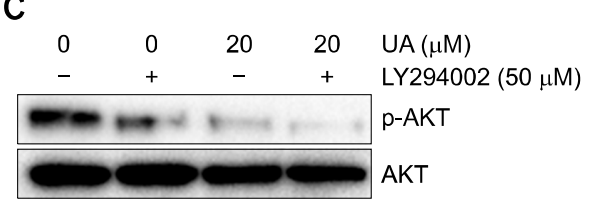

E

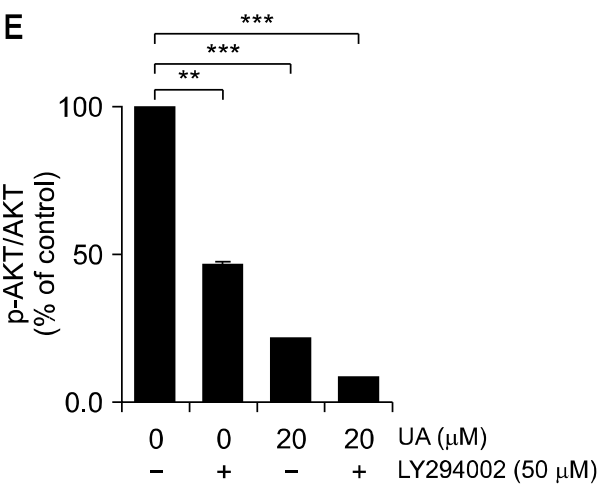

Fig. 7. Effect of ursolic acid (UA) on ERK and PI3K/AKT signaling pathways in MCF-7 cell-derived breast cancer stem (BCS)-like cells. (A) Representative blots showing protein expression of ERK and PI3K/AKT in MCF-7 cell-derived BCS-like cells treated with $\mathrm{UA}$ at 5,10 , and $20 \mu \mathrm{M}$ for $24 \mathrm{~h}$. (B and C) Cells were treated with UA in combination with the ERK inhibitor PD98059 or the AKT inhibitor LY294002, and levels of p-ERK or p-AKT were detected by Western blotting. (D and E) Band intensities were normalized to total ERK or AKT. Results are presented as mean \pm SD. ${ }^{* *} P<0.01$ and ${ }^{* * *} P<$ 0.001 compared to total ERK or AKT.
p-ERK and p-AKT activation was significantly suppressed $(P<0.01$ and $P<0.001$, respectively; Fig. 7D and 7E). These results suggest that ERK and PI3K/AKT signaling pathways are in part associated with inhibition of cell growth by UA.

\section{DISCUSSION}

Due to the global increase in breast cancer incidence, development of effective drugs and treatments targeting BCSCs has been a focus of recent research (Butti et al., 2019; Duan et al., 2021). Various therapeutic approaches for breast cancer management, including surgery, radiotherapy, chemotherapy, and hormonal therapy, are currently employed in clinical practice (Tong et al., 2018). Nevertheless, cancer relapse and metastasis result in a poor prognosis (Feng et al., 2018). The main cause of cancer progression is the presence of BCSCs, a class of pluripotent cancer cells with distinctive characteristics of self-renewal, high rates of proliferation, and the ability to differentiate into a spectrum of cell types observed in tumors (Velasco-Velázquez et al., 2011). In general, chemotherapy has various side effects, including toxic effects on normal cells and development of drug resistance (Kern and Schroeder, 2014). Therefore, it is crucial to identify novel natural compounds that are able to specifically inhibit cancer cell proliferation with low cytotoxicity to- wards non-cancer cells (Li-Weber, 2009). Many studies have focused on phytochemicals that target BCSCs (Dandawate et al., 2016), which has led to the growing interest in natural compounds that can be exploited to target BCSCs for effective anticancer therapy. In the current study, we provide the first evidence that UA at concentrations of $5 \sim 20 \mu \mathrm{M}$ suppresses MCF-7 cell proliferation whilst exhibiting low cytotoxicity and without inducing morphological changes (Fig. 1B). Moreover, we show that UA effectively reduces migration and colony formation (mammosphere formation) in MCF-7 cells and MCF-7 cell-derived BCS-like cells (Fig. 3 and 6).

The tumor suppressor gene $p 53$ plays a critical role in mediating cellular responses by regulating transcriptional activation of various genes involved in apoptosis, cell cycle arrest, and DNA repair (Harris and Levine, 2005). p53 also induces transcription of p21, an important regulator of the cell cycle. The cyclin-CDK complex plays a central role in the regulation of cell cycle progression. p21 is an inhibitor of CDK expression and can inhibit cyclinCDK complex formation to induce cell cycle arrest. In the current study, treatment of MCF-7 cells with UA increased p53 and p21 expression, thereby inhibiting the breast cancer cell cycle (Fig. 2C). Furthermore, UA activated p38 MAPK, an important stress-related kinase involved in regulation of inflammation, cell growth and differentiation, cell cycle, and cell death (Fig. 2C) (MacCorkle and Tan, 2005). 
CSCs derived from cancer cells are potential targets for breast cancer therapy (Liu et al., 2013). In the present study, UA exerted a significantly greater cytotoxic on MCF-7 cell-derived BCS-like cells than on MCF-7 cells. These results indicate that UA has a selective inhibitory effect on the growth of BCSCs (Fig. 5). The current chemotherapeutic target is CSCs, an important cause of cancer relapse (Butti et al., 2019; De Angelis et al., 2019). Three subtypes of BCSCs have been identified: mesenchymal-like $\mathrm{CD} 44^{\text {high }} / \mathrm{CD} 24^{\text {low }}$, epithelial-like $\mathrm{ALDH}^{+}$, and $\mathrm{ALDH}^{+} / \mathrm{CD} 44^{\text {high }} / \mathrm{CD} 24^{\text {low }}$ (Sulaiman et al., 2019). CD44 is a non-kinase, single-span transmembrane glycoprotein that binds to hyaluronan, regulating cell proliferation, survival, and differentiation. The expression of CD44 in BCSCs is high, and downregulation of CD44 induces cell differentiation and sensitization to chemotherapy (Pham et al., 2011; Yan et al., 2015). Whereas CD24 is a glycosylphosphatidylinositol-linked cell surface glycoprotein involved in immunological functions, tumorigenesis, chemoresistance, and metastasis. CD24 expression in BCSCs is low or absent, and upregulation of CD24 is associated with a poor prognosis in luminal $\mathrm{A}$ and triple-negative breast cancer subtypes (Ortiz-Montero et al., 2018). Furthermore, ALDH is a member of a group of enzymes that oxidize aldehydes into carboxylic acids. High ALDH activity, as measured by ALDEFLUOR assays (which assess levels of nine active isoforms of ALDH), is associated with stem cell-like properties and chemoresistance in breast cancer, while inhibition of ALDH suppresses tumorigenicity and cell migration (Li et al., 2017). To examine the differentiation capacity of BCSCs, $\mathrm{CD}_{4} 4^{+} /$ $\mathrm{CD} 24^{-/ \text {low }}$ and $\mathrm{ALDH}^{+}$cell populations were analyzed as differentiation markers. After 28 days differentiation, the $\mathrm{CD} 44^{+} / \mathrm{CD} 24^{- \text {low }}$ cell population increased from $0.83 \%$ to $26.19 \%$, while the ALDH-positive cell population increased from $14.16 \%$ to $41.30 \%$ (Fig. 4).

Numerous natural compounds exert inhibitory effects on CSCs by interfering with multiple targets in cancerrelated signaling pathways (Yang et al., 2020). Thus, natural compounds can be used to develop novel chemotherapeutic agents targeting BCSCs (Liskova et al., 2019). Among cancer-related signaling pathways, the association between cell proliferation and the ERK pathway is clearly established. The ERK signaling pathway controls cyclin D1 expression and S phase progression in embryonic stem cells in mice (Jirmanova et al., 2002). Furthermore, the PI3K/AKT signaling pathway plays an important role in intracellular signal transduction and cell proliferation, differentiation, division, and migration ( $\mathrm{Li}$ et al., 2013), and PI3K activity contributes substantially to cellular transformation and carcinogenesis (Fresno Vara et al., 2004). As AKT is a major effector in the PI3K signaling pathway, an increase in AKT activity blocks the apoptotic pathway (Shin et al., 2012). Regulation of the
$\mathrm{PI} 3 \mathrm{~K} / \mathrm{AKT}$ pathway is likely to be central in specifically targeting cancer cells using chemotherapeutic agents without inducing cytotoxicity to normal cells. Thus, the findings of the present study confirmed the role of UA in reducing PI3K expression in MCF-7 cell-derived BCS-like cells and, consequently, lowering AKT levels to delay cancer progression. UA also suppressed p-ERK but upregulated p-FoxO1/FoxO3a to induce cell cycle arrest in the G1 phase and to inhibit cancer cell proliferation (Fig. 7).

In conclusion, the selective effects of UA on BCSCs were determined for the first time. We demonstrated that a low concentration of UA inhibits proliferation of MCF-7 cell-derived BCS-like cells. Furthermore, UA inhibits cell proliferation by targeting the ERK and PI3K/AKT signaling pathways in MCF-7 cell-derived BCS-like cells, thus suppressing progression of breast cancer. These findings support the use of UA as a novel inhibitor of the ERK and PI3K/AKT signaling pathways in breast cancer therapy. Thus, UA is a candidate therapeutic agent for targeting BCSCs.

\section{ACKNOWLEDGEMENTS}

This work was supported by National Research Foundation of Korea (NRF) grant funded by the Korea government (MSIT) (grant number 2017R1D1A3B03034506, 2020R1F1A1072191).

\section{AUTHOR DISCLOSURE STATEMENT}

The author declares no potential conflict of interest.

\section{REFERENCES}

Bak MJ, Das Gupta S, Wahler J, Suh N. Role of dietary bioactive natural products in estrogen receptor-positive breast cancer. Semin Cancer Biol. 2016. 40-41:170-191.

Brunetti A, Manfioletti G. Editorial: hormone receptors and breast cancer. Front Endocrinol. 2019. 10:205. https://doi.org/10. 3389/fendo.2019.00205

Butti R, Gunasekaran VP, Kumar TVS, Banerjee P, Kundu GC. Breast cancer stem cells: biology and therapeutic implications. Int J Biochem Cell Biol. 2019. 107:38-52.

Choi HS, Kim SL, Kim JH, Deng HY, Yun BS, Lee DS. Triterpene acid (3-O-p-coumaroyltormentic acid) isolated from aronia extracts inhibits breast cancer stem cell formation through downregulation of c-Myc protein. Int J Mol Sci. 2018. 19:2528. https://doi.org/10.3390/ijms19092528

Dandawate PR, Subramaniam D, Jensen RA, Anant S. Targeting cancer stem cells and signaling pathways by phytochemicals: novel approach for breast cancer therapy. Semin Cancer Biol. 2016. 40-41:192-208.

De Angelis ML, Francescangeli F, Zeuner A. Breast cancer stem cells as drivers of tumor chemoresistance, dormancy and reapse: new challenges and therapeutic opportunities. Cancers. 
2019. 11:1569. https://doi.org/10.3390/cancers11101569

Dérijard B, Raingeaud J, Barrett T, Wu IH, Han J, Ulevitch RJ, et al. Independent human MAP-kinase signal transduction pathways defined by MEK and MKK isoforms. Science. 1995. 267: 682-685.

Duan H, Liu Y, Gao Z, Huang W. Recent advances in drug delivery systems for targeting cancer stem cells. Acta Pharm Sin B. 2021. 11:55-70.

Farvid MS, Chen WY, Michels KB, Cho E, Willett WC, Eliassen $\mathrm{AH}$. Fruit and vegetable consumption in adolescence and early adulthood and risk of breast cancer: population based cohort study. BMJ. 2016. 353:i2343. https://doi.org/10.1136/bmj. i2343

Feng Y, Spezia M, Huang S, Yuan C, Zeng Z, Zhang L, et al. Breast cancer development and progression: risk factors, cancer stem cells, signaling pathways, genomics, and molecular pathogenesis. Genes Dis. 2018. 5:77-106.

Fresno Vara JA, Casado E, de Castro J, Cejas P, Belda-Iniesta C, González-Barón M. PI3K/Akt signalling pathway and cancer. Cancer Treat Rev. 2004. 30:193-204.

Grosso G, Bella F, Godos J, Sciacca S, Del Rio D, Ray S, et al. Possible role of diet in cancer: systematic review and multiple metaanalyses of dietary patterns, lifestyle factors, and cancer risk. Nutr Rev. 2017. 75:405-419.

Harris SL, Levine AJ. The 553 pathway: positive and negative feedback loops. Oncogene. 2005. 24:2899-2908.

Hernandez-Aya LF, Gonzalez-Angulo AM. Targeting the phosphatidylinositol 3-kinase signaling pathway in breast cancer. Oncologist. 2011. 16:404-414.

Jafari SM, Joshaghani HR, Panjehpour M, Aghaei M, Zargar Balajam N. Apoptosis and cell cycle regulatory effects of adenosine by modulation of GLI- 1 and ERK1/2 pathways in CD $44^{+}$ and CD24 $4^{-}$breast cancer stem cells. Cell Prolif. 2017. 50: e12345. https://doi.org/10.1111/cpr.12345

Jiang X, Li T, Liu RH. $2 \alpha$-Hydroxyursolic acid inhibited cell proliferation and induced apoptosis in MDA-MB-231 human breast cancer cells through the p38/MAPK signal transduction pathway. J Agric Food Chem. 2016. 64:1806-1816.

Jirmanova L, Afanassieff M, Gobert-Gosse S, Markossian S, Savatier P. Differential contributions of ERK and PI3-kinase to the regulation of cyclin D1 expression and to the control of the $\mathrm{Gl} / \mathrm{S}$ transition in mouse embryonic stem cells. Oncogene. 2002. 21:5515-5528.

Kassi E, Sourlingas TG, Spiliotaki M, Papoutsi Z, Pratsinis H, Aligiannis N, et al. Ursolic acid triggers apoptosis and Bcl-2 downregulation in MCF-7 breast cancer cells. Cancer Invest. 2009. 27:723-733.

Kern KM, Schroeder JR. Comparison of cantharidin toxicity in breast cancer cells to two common chemotherapeutics. Int J Breast Cancer. 2014. 2014:423059. https://doi.org/10.1155/ 2014/423059

Li W, Ma H, Zhang J, Zhu L, Wang C, Yang Y. Unraveling the roles of CD44/CD24 and ALDH1 as cancer stem cell markers in tumorigenesis and metastasis. Sci Rep. 2017. 7:13856. https:// doi.org/10.1038/s41598-017-14364-2

Li Y, Jiang Y, Wan Y, Zhang L, Tang W, Ma J, et al. Medroxyprogestogen enhances apoptosis of SKOV-3 cells via inhibition of the PI3K/Akt signaling pathway. J Biomed Res. 2013. 27:4350.

Liskova A, Kubatka P, Samec M, Zubor P, Mlyncek M, Bielik T, et al. Dietary phytochemicals targeting cancer stem cells. Molecules. 2019. 24:899. https://doi.org/10.3390/molecules2405 0899

Liu P, Du R, Yu X. Retracted: ursolic acid exhibits potent anticancer effects in human metastatic melanoma cancer cells (SKMEL-24) via apoptosis induction, inhibition of cell migration and invasion, cell cycle arrest, and inhibition of mitogen-acti- vated protein kinase (MAPK)/ERK signaling pathway. Med Sci Monit. 2021. 27:e930758. https://doi.org/10.12659/ MSM.930758

Liu S, Cong Y, Wang D, Sun Y, Deng L, Liu Y, et al. Breast cancer stem cells transition between epithelial and mesenchymal states reflective of their normal counterparts. Stem Cell Reports. 2013. 2:78-91.

Li-Weber M. New therapeutic aspects of flavones: the anticancer properties of Scutellaria and its main active constituents Wogonin, Baicalein and Baicalin. Cancer Treat Rev. 2009. 35:5768.

Lombardo Y, de Giorgio A, Coombes CR, Stebbing J, Castellano L. Mammosphere formation assay from human breast cancer tissues and cell lines. J Vis Exp. 2015. 97:52671. https://doi. org/10.3791/52671

LoPiccolo J, Blumenthal GM, Bernstein WB, Dennis PA. Targeting the PI3K/Akt/mTOR pathway: effective combinations and clinical considerations. Drug Resist Updat. 2008. 11:32-50.

Lumachi F, Santeufemia DA, Basso SM. Current medical treatment of estrogen receptor-positive breast cancer. World J Biol Chem. 2015. 6:231-239.

MacCorkle RA, Tan TH. Mitogen-activated protein kinases in cell-cycle control. Cell Biochem Biophys. 2005. 43:451-461.

Marone R, Cmiljanovic V, Giese B, Wymann MP. Targeting phosphoinositide 3-kinase: moving towards therapy. Biochim Biophys Acta. 2008. 1784:159-185.

Nandy SB, Lakshmanaswamy R. Cancer stem cells and metastasis. Prog Mol Biol Transl Sci. 2017. 151:137-176.

Ortiz-Montero P, Liu-Bordes WY, Londoño-Vallejo A, Vernot JP. CD24 expression and stem-associated features define tumor cell heterogeneity and tumorigenic capacities in a model of carcinogenesis. Cancer Manag Res. 2018. 10:5767-5784.

Pham PV, Phan NL, Nguyen NT, Truong NH, Duong TT, Le DV, et al. Differentiation of breast cancer stem cells by knockdown of CD44: promising differentiation therapy. J Transl Med. 2011. 9:209. https://doi.org/10.1186/1479-5876-9-209

Reddy KB, Nabha SM, Atanaskova N. Role of MAP kinase in tumor progression and invasion. Cancer Metastasis Rev. 2003. 22:395-403.

Shan JZ, Xuan YY, Ruan SQ, Sun M. Proliferation-inhibiting and apoptosis-inducing effects of ursolic acid and oleanolic acid on multi-drug resistance cancer cells in vitro. Chin J Integr Med. 2011. 17:607-611.

Shan NL, Shin Y, Yang G, Furmanski P, Suh N. Breast cancer stem cells: a review of their characteristics and the agents that affect them. Mol Carcinog. 2021. 60:73-100.

Shin DY, Kim GY, Lee JH, Choi BT, Yoo YH, Choi YH. Apoptosis induction of human prostate carcinoma DU145 cells by diallyl disulfide via modulation of JNK and PI3K/AKT signaling pathways. Int J Mol Sci. 2012. 13:14158-14171.

Simões BM, Piva M, Iriondo O, Comaills V, López-Ruiz JA, Zabalza I, et al. Effects of estrogen on the proportion of stem cells in the breast. Breast Cancer Res Treat. 2011. 129:23-35.

Singh JK, Farnie G, Bundred NJ, Simões BM, Shergill A, Landberg $\mathrm{G}$, et al. Targeting CXCR1/2 significantly reduces breast cancer stem cell activity and increases the efficacy of inhibiting HER2 via HER2-dependent and -independent mechanisms. Clin Cancer Res. 2013. 19:643-656.

Sulaiman A, McGarry S, Han X, Liu S, Wang L. CSCs in breast cancer-one size does not fit all: therapeutic advances in targeting heterogeneous epithelial and mesenchymal CSCs. Cancers. 2019. 11:1128. https://doi.org/10.3390/cancers11081128

Thomas W, Coen N, Faherty S, Flatharta CO, Harvey BJ. Estrogen induces phospholipase A2 activation through ERK1/2 to mobilize intracellular calcium in MCF-7 cells. Steroids. 2006. 71: 256-265.

Tong CWS, Wu M, Cho WCS, To KKW. Recent advances in the 
treatment of breast cancer. Front Oncol. 2018. 8:227. https:// doi.org/10.3389/fonc.2018.00227

Velasco-Velázquez MA, Popov VM, Lisanti MP, Pestell RG. The role of breast cancer stem cells in metastasis and therapeutic implications. Am J Pathol. 2011. 179:2-11.

Visvader JE, Lindeman GJ. Cancer stem cells in solid tumours: accumulating evidence and unresolved questions. Nat Rev Cancer. 2008. 8:755-768.

Wang JS, Ren TN, Xi T. Ursolic acid induces apoptosis by suppressing the expression of FoxM1 in MCF-7 human breast cancer cells. Med Oncol. 2012. 29:10-15.

Wu HJ, Chu PY. Role of cancer stem cells in cholangiocarcinoma and therapeutic implications. Int J Mol Sci. 2019. 20:4154. https://doi.org/10.3390/ijms20174154

Yan Y, Zuo X, Wei D. Concise review: emerging role of CD44 in cancer stem cells: a promising biomarker and therapeutic target. Stem Cells Transl Med. 2015. 4:1033-1043.

Yang L, Shi P, Zhao G, Xu J, Peng W, Zhang J, et al. Targeting can- cer stem cell pathways for cancer therapy. Signal Transduct Target Ther. 2020. 5:8. https://doi.org/10.1038/s41392-0200110-5

Yeh CT, Wu CH, Yen GC. Ursolic acid, a naturally occurring triterpenoid, suppresses migration and invasion of human breast cancer cells by modulating c-Jun N-terminal kinase, Akt and mammalian target of rapamycin signaling. Mol Nutr Food Res. 2010. 54:1285-1295.

Yin R, Li T, Tian JX, Xi P, Liu RH. Ursolic acid, a potential anticancer compound for breast cancer therapy. Crit Rev Food Sci Nutr. 2018. 58:568-574.

Yousefnia S, Naseri D, Seyed Forootan F, Tabatabaeian M, Moattar F, Ghafghazi T, et al. Suppressive role of Viola odorata extract on malignant characters of mammosphere-derived breast cancer stem cells. Clin Transl Oncol. 2020. 22:16191634.

Zhao J. Cancer stem cells and chemoresistance: the smartest survives the raid. Pharmacol Ther. 2016. 160:145-158. 